\title{
FROM THE DISCOVERY OF RADIOACTIVITY TO THE DEVELOPMENT OF THE K-Ar DATING METHOD
}

\author{
STANISŁAW HALAS \\ Mass Spectrometry Laboratory, Maria Curie-Skłodowska University, \\ pl. M. Curie Skłodowskiej 1, 20-031 Lublin, Poland
}

Received 1 February 2012

Accepted 27 April 2012

\begin{abstract}
In this paper I try to explain why the potassium-argon dating method was developed much later than other radiometric methods (like $\mathrm{U}-\mathrm{He}$ and $\mathrm{U}-\mathrm{Pb}$ ), which were established at the beginning of the $20^{\text {th }}$ century. In fact the pioneering paper by Aldrich and Nier (1948) was published 50 years after the discovery of polonium and radium, when nearly all the details concerning potassium isotopes and radioactivity of potassium- 40 had been investigated. The role of Marie Curie's concept of the nature of radioactivity in the discovery of the radioactivity of potassium is emphasized.
\end{abstract}

Keywords: argon, isotopes, radioactivity, potassium, dating, mass spectrometer.

\section{INTRODUCTION}

$\mathrm{K}-\mathrm{Ar}$ dating belongs to the methods most useful in answering various geochronological questions, due to the high precision of obtained dates and the large abundance of potassium in rock-forming minerals. The relative standard deviation of dates is typically less than $\pm 1 \%$, which helps establish the stratigraphical boundaries within the entire history of the Earth. This is just one example of many more applications of this excellent dating method.

The K-Ar method along with many other methods of geochronology is based on the law of radioactive decay discovered at the beginning of the $20^{\text {th }}$ century. This law describes the indeterministic process occurring in nature, which appears to be the radioactive transmutation of a chemical element. This process is not "statistical" in the $19^{\text {th }}$ century sense, reflecting our ignorance of the specific conditions under which individual atoms of an ensemble will decay, but it is described by the $20^{\text {th }}$ century statistics in the sense of reflecting the average decay rate of a given

Corresponding author: S. Hałas

e-mail: stanislaw.halas@umcs.pl ensemble of atoms. This means that the relative decay rate of the whole ensemble remains constant at any instant.

The K-Ar method has a long and fascinating history. The pioneering work in this field by Aldrich and Nier (1948) "Argon-40 in potassium minerals" appeared 50 years after the discovery of radioactivity. It is the intention of this paper to describe the 60-year-long history between the discovery of the radioactivity and the development of the potassium-argon dating method of geological samples.

\section{THE DISCOVERY OF RADIOACTIVITY}

The radioactivity of uranium was discovered shortly after Röntgen's discovery of X-rays (on the evening of $8^{\text {th }}$ November 1895). Röntgen wrote a 10-page article entitled "On a new kind of rays", which was accepted by the Proceedings of the Würzburg Physical-Medical Society on 28 December 1895.

In January 20, 1896 Henri Poincaré discussed Röntgen's unexpected discovery during a meeting of the 
Academy of Sciences in Paris and presented his hypothesis that the emission of radiation by uranium may be another kind of fluorescence. Becquerel tested this hypothesis in his laboratory with the uranylum salt. He exposed a sample to sunlight, wrapped it with black paper and placed it on a photographic plate. The result appeared to confirm Poincare's hypothesis - the plate was blackened! Becquerel presented this result in the Academy meeting at 24 February 1896 . He repeated this experiment without exposure to sunlight and got the same result. In the next meeting at 2 March he concluded that the uranium salt itself must be the source of the unknown highly penetrating radiation.

Based on the results of subsequent experiments Becquerel found that the rays emitted by uranium have a shorter penetration depth in air than those emitted from uranium salts, which have a larger intensity than those obtained from uranium metal. He used an electrically charged electroscope (alike the one used by Röntgen) as another detector of uranium rays and noticed that the electroscope was discharged in much slower rate than in the case of X-rays.

\section{THE DISCOVERY OF POLONIUM AND RADIUM}

In 1897 Maria Skłodowska-Curie started systematic investigations of the Becquerel's rays measuring their impact on the air conductivity with a device invented by Pierre Curie. One of the two capacitor plates was covered with a uniform layer of uranium or uranium salts. She applied a voltage of 100 volts and measured the electric current with an electrometer balanced by a piezoelectric quartz crystal. She found that:

1) The activity (defined as electric current between the plates of the capacitor) of uranium salts is interrelated to their uranium content.

2) Thorium compounds have a large activity.

3) Two uranium ores, pitchblende and chalcolite (crystallized phosphate of copper and uranium), have a larger activity than elemental uranium. SkłodowskaCurie concluded that these minerals contain at least one radioactive element different than uranium.

Skłodowska-Curie (1898) described these results in her paper "Emission of rays by uranium and thorium compounds" published in May 1898 and introduced the term radioactivity (independently from Schmidt). She also presented her first hypothesis on the nature of radiation as a property of elements with large molar masses as $\mathrm{U}$ and Th. She claimed for them the strongest absorption capability and subsequent reemission of ultra-penetrative $\mathrm{X}$-rays which always traverse the space around. Her discoveries have been considered by Professor A. K. Wróblewski (1997) as the beginning of radioactivity as a new branch of science.

Later on Skłodowska-Curie extended her investigations on radioactivity in her $\mathrm{PhD}$ Thesis "Investigations of radioactive bodies" to search for new radioactive ele- ments and to study their properties. In July 1898 Maria and Pierre Curie reported the discovery of a new radioactive element extracted from pitchblende. It had similar chemical properties to bismuth. They named it polonium referring to the "home-country name of one of us" (Curie and Curie, 1898). The discovery was also published in the Polish Journal "Czasopismo Techniczne" in August 10, 1898 (Halas, 1998).

In December 1898 Marie and Pierre Curie together with G. Bémont succeeded for the second time in extracting another new element from pitchblende. It had chemical properties similar to barium and was named radium (Curie et al., 1898). The discovery of Po and Ra inspired a number of scientists to study the phenomenon of radioactivity. In connection to the above findings, the radioactive gases (emanates) emitted from radium and thorium were detected independently by Dorn and Rutherford in 1900, see Rutherford (1906). For their discoveries, Maria and Pierre Curie received Nobel Prize in 1903, which they shared with $\mathrm{H}$. Becquerel. Due to various circumstances the Curie's Nobel lecture was postponed until June 1905.

In the Nobel Lecture "On radioactive substances" Pierre Curie (1905) presented two ideas on the nature of radioactivity: (1) $\mathrm{U}$, Th and Ra convert the energy of highly penetrating radiation as first hypothesized by Maria Curie. (2) The radioactive elements emit rays of high energy by transmutations similar to chemical reactions. Pierre Curie was in favor to the second hypothesis based on the Boltwood's finding of a constant ratio of $\mathrm{U} / \mathrm{Ra}$ in the studied minerals.

\section{THE BEGINNING OF RADIOMETRIC DATING}

Already at the end of the XIX century Rutherford stated that the radioactive decay may be used to date quantitatively the minerals containing radioactive elements. This was possible after the discovery of the decay equation by Rutherford and Soddy (1902a, 1902b):

$N=N_{o} \exp (-\lambda \mathrm{t})$,

where $N_{o}$ and $N$ are initial number of radioactive atoms and the number which remains in a sample after time $t$, respectively. The parameter $\lambda$ is known as decay constant and it characterizes the decay rate, i.e. activity $d N / d t$, of a radioactive element. The activity of a radioactive element is directly proportional to the number of atoms $N$ at any time:

$d N / d t=-\lambda N$.

The parameter $\lambda$ is simply related to the mean time of life of the radioactive element $\tau=1 / \lambda$ and to its half-life $T_{1 / 2}=(\ln 2) / \lambda$. By the definition, after time $\tau$ and $T_{1 / 2}$ the number of radioactive atoms will drop to $1 / \mathrm{e}=0.3678 \ldots$ and to $1 / 2$ of their initial number, respectively. Both equations (Eq. 4.1 and 4.2) are mathematically equivalent. Formula (4.2) can be derived by differentiation of 
Eq. 4.1, whereas Eq. 4.1 can be derived by integration of Eq. 4.2. From the point of view of the probability theory the decay equation describes an entirely statistical process. At any infinitesimal interval of time $(t, t+d t)$ the probability of the radioactive decay is the same for all $N$ atoms remaining in the sample. The statistical nature of this law is illustrated by original Rutherford's drawings in Fig. 1.

In 1906 E. Rutherford presented the first dates from uranium minerals obtained from measured $\mathrm{U}$ and $\mathrm{He}$ concentrations. The nature of $\alpha, \beta$ and $\gamma$ radiation was already well understood thanks to studies by F.O. Giesel, S. Meyer, E.R. von Schweidler, H. Becquerel and by Rutherford himself. These three types of radiation were discovered and named before 1900. Rutherford with his coworkers in Montreal recognized $\alpha$ particles as helium ions by precise experiments comparing physical properties of both species (Rutherford, 1906).

Boltwood (1907) developed the U-Pb dating method based on the determination of these two elements, which were determined analytically. These pioneering works founded a new field of science, the geochronometry. The first dates provided evidence that minerals of the Earth's crust may be as old as several hundred million years and therefore considerably older than $30 \mathrm{Ma}$ as suggested by Lord Kelvin for the age of Earth.

\section{DISCOVERY OF RADIOACTIVITY OF POTAS- SIUM}

According to Marie Curie's first hypothesis on the nature of radioactivity, only elements with large atomic masses are capable of absorption (and subsequent reemission) of the high-energy radiation that permanently traverses the space. For this reason attempts were made to search for the element with atomic number 87 . This heavy element with the tentative name ekacesium

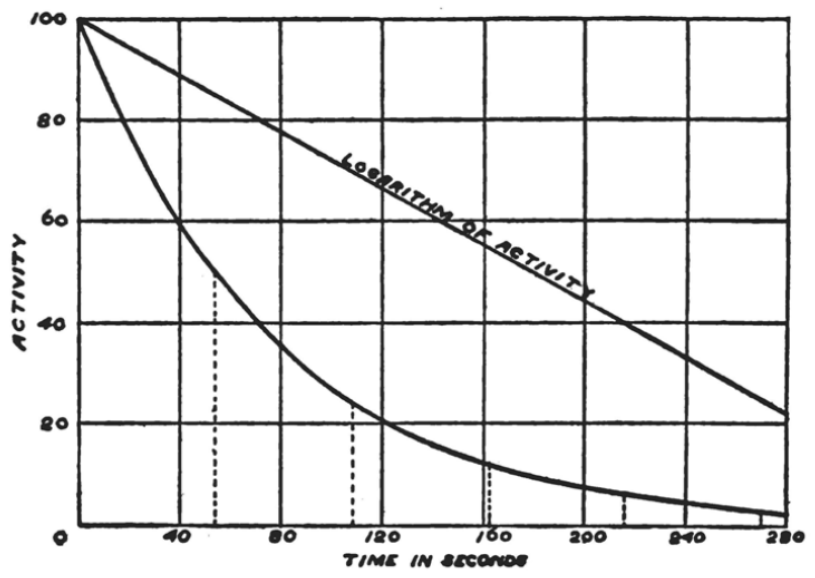

Fig. 1. Decay of activity of the radioactive gas emitted by thorium, called emanation. Dotted lines point successive half-life periods evaluated as 54 seconds (Rutherford, 1906).
(= beyond cesium) was not discovered yet, but its existence was suspected for the sake of completeness of the first group of the periodic table. This radioactive element might be an admixture to alkali metals. Finally, Maria and Pierre Curie succeeded and discovered two other radioactive elements among the alkaline metals - rubidium and potassium.

In 1905 J.J. Thomson demonstrated experimentally that rubidium and $\mathrm{Rb}-\mathrm{Na}$ alloy emits negatively charged particles. He placed samples near a sensitive electroscope (Fig. 2) in a dark room to avoid the influence of light and found that a positively charged electroscope was discharged. In contrast, a negatively charged electroscope was not affected. Moreover, Thomson discovered that the discharge of the electroscope stopped if an external magnetic field was aligned perpendicularly to the sampleelectroscope direction. Similar experiments with other heavy metals as mercury, lead and silver failed in contrary to the expectations by $\mathrm{M}$. Curie that heavy elements should absorb highly penetrative ambience radiation and re-emit it immediately as less penetrative rays, which can be detected by her sensitive ionization chamber method.

\section{POTASSIUM ISOTOPES}

In $1911 \mathrm{~F}$. Soddy demonstrated the chemical identity of meso-thorium and radium. He also noticed another peculiarity of radioactive materials: lead obtained by decay of uranium and thorium differed in atomic mass. Subsequently Kasimir Fajans (1913) and Frederick Soddy (1913) described the rules of transformation of elements in connection with the radioactive decay and they introduced the term isotopes to account for their identical

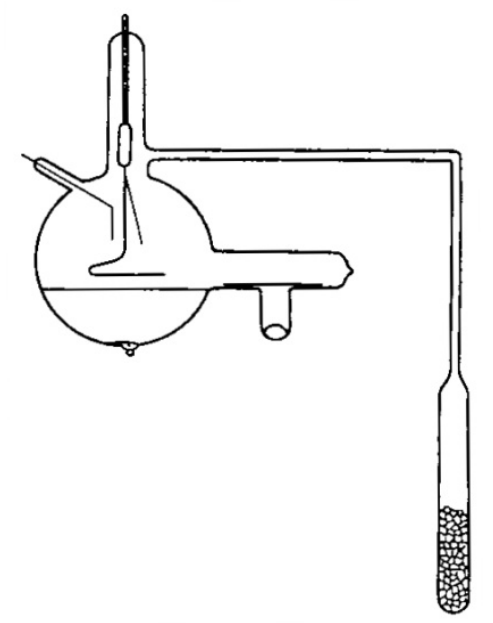

Fig. 2. Electroscope used by Thomson (1905) to detect charged particles emitted from radioactive rubidium in an evacuated glass apparatus. There are two electrodes (top and left), the sample container (right) and a delicate gold foil attached to the vertical electrode. The foil shifts away and up if both electrodes are charged and falls down upon the discharge. 
position in the periodic table (Greek isos topos $=$ in the same place). The question of the existence of atoms of a chemical element with different masses came up when the instruments developed by J.J. Thomson and by W. Wien to study cathode and canal rays by deflection in electric and magnetic fields were steadily improved. In 1913 J.J. Thomson mentioned a weak line at mass 22 accompanying the expected line at mass 20 when he analyzed the mass spectrum of neon. This provided an explanation for the measured atomic weight of 20.2 of naturally occurring neon. Subsequently F.W. Aston obtained the mass spectrum of chlorine with masses at 35 and 37.

In 1921 Aston constructed a new kind of ion source (Fig. 3) for the Thomson's instrument employing parallel electric and magnetic fields in order to determine the mass to charge ratio of ions. This source allowed him to utilize the thermal ionization of atoms of alkali metals. Aston investigated all the alkali metals and found two isotopes for $\mathrm{Li}, \mathrm{K}$ and $\mathrm{Rb}$, and one isotope for $\mathrm{Na}$ and $\mathrm{Cs}$. The masses of these isotopes were determined with low precision - those of potassium were close to 39 and 41.

Once the isotopic composition of potassium was known, attempts were made to recognize which one is radioactive. In 1928 Biltz and Ziegert enriched potassium in heavy isotopes by their distillation and found that ${ }^{39} \mathrm{~K}$ is stable and ${ }^{41} \mathrm{~K}$ or another potassium isotope with very low abundance must be radioactive. In 1933 Aston argued that ${ }^{41} \mathrm{~K}$ is stable, because he did not see even a trace of ${ }^{41} \mathrm{Ca}$ isotope in the mass spectrum of calcium extracted from very old biotite samples. Based on this result, Neuman and Walke (1935) assumed that another undiscovered isotope, such as ${ }^{40} \mathrm{~K}$ or ${ }^{42} \mathrm{~K}$, must be responsible for the radioactivity of potassium. They persuasively argued that the radioactive isotope is probably ${ }^{40} \mathrm{~K}$, yielding ${ }^{40} \mathrm{Ca}$ as the daughter product by $\beta^{-}$decay. They also suggested another possibility of ${ }^{40} \mathrm{~K}$ decay, namely to ${ }^{40} \mathrm{Ar}$. On the other hand E. Fermi and his coworkers (1934) determined the half-life of ${ }^{42} \mathrm{~K}$ artificial isotope, obtained by neutron bombardment of natural potassium, and got 16 hours. Therefore Neuman and Walke (1935) concluded that only the ${ }^{40} \mathrm{~K}$ isotope is responsible for radioactivity of natural potassium.

In the first edition of Aston's book on "Mass Spectra and Isotopes" published in 1933, the upper limit for con- centration of the yet undiscovered ${ }^{40} \mathrm{~K}$ isotope was estimated from the instrumental sensitivity to be lower than 1/300. Von Hevesy (1935) concluded that the sole longlived potassium isotope is ${ }^{40} \mathrm{~K}$ and proposed the following decay scheme:

${ }^{40} \mathrm{~K}=>{ }^{40} \mathrm{Ca}+\beta^{-}+\gamma$

He estimated the half-life of ${ }^{40} \mathrm{~K}$ to be between $5 \cdot 10^{10}$ and $500 \cdot 10^{10}$ years.

Nier (1935) and later Brewer (1935) searched for the ${ }^{40} \mathrm{~K}$ isotope and determined precisely the potassium isotope ratios with a very sensitive mass spectrometer. These instruments had a sector magnetic field which provided very good resolution of the ion beams produced in the thermal ionization ion source with respect to their masses. The isotope ions were detected with a Faraday cup connected to a sensitive electrometer. A mass spectrum (Fig. 4) was obtained by varying the strength of the magnetic field and measurement of the positive ion current. They excluded any interference in the potassium mass spectrum from ${ }^{40} \mathrm{Ca}$, the most abundant isotope of calcium, by applying significantly lower temperatures than needed for calcium ionization. The following ratios of isotope concentrations were obtained by Nier (1935):

${ }^{39} \mathrm{~K} /{ }^{40} \mathrm{~K}=8300 \pm 100$ and ${ }^{39} \mathrm{~K} /{ }^{41} \mathrm{~K}=13.96$

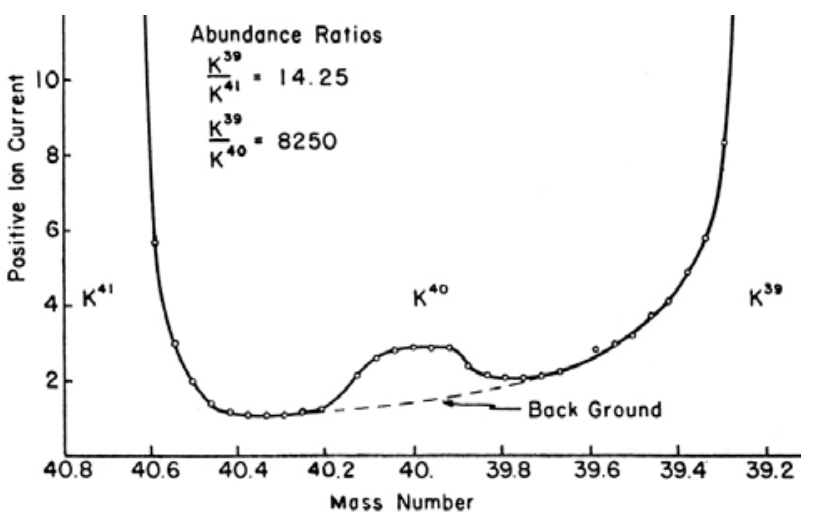

Fig. 4. The central part of mass spectrum of potassium with peak of 40 K (Brewer, 1935)

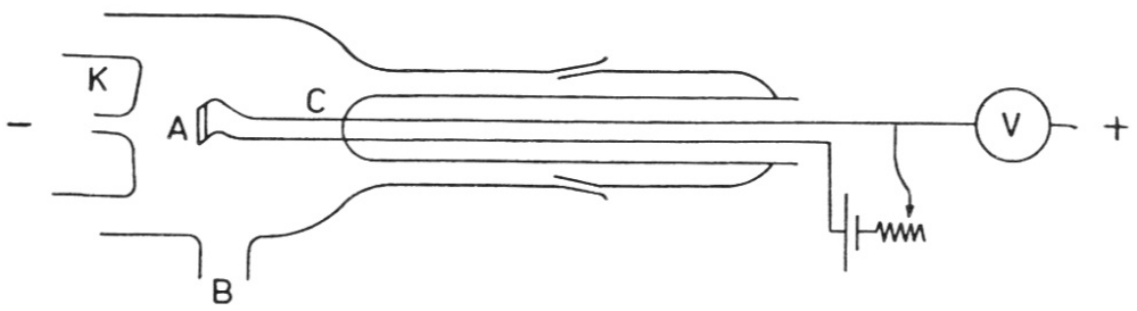

Fig. 3. Schematic drawing of the ion source (Aston, 1921). Positive ions are emitted from a heated platinum filament $A$ in the vacuum and accelerated within the space between the filament and the electrode $K$. 


\section{SCHEME OF ${ }^{40} \mathrm{~K}$ DECAY}

In an earlier work Baxter and MacNevin (1933) stated that the isotope ${ }^{40} \mathrm{~K}$ (hypothetical at that time) is stable and the radioactivity of potassium is attributed to the isotope ${ }^{41} \mathrm{~K}$. This uncertainty could only be solved with help of experiments performed on the isolated potassium isotopes. The separation was done by Smythe and Hemmendinger (1937) at CALTECH in Pasadena, who separated 3 isotopes of potassium by means of a high efficiency mass spectrometer. They demonstrated with a Geiger-Müller counter (the device for counting individual rays traversing through it, invented by the two Rutherford's coworkers and named after them) that only ${ }^{40} \mathrm{~K}$ emits beta particles. The measured activity of this isotope, defined by formula (2), was comparable with the activity of a respective quantity of $\mathrm{KCl}$ salt. Therefore Smythe and Hemmendinger (1937) proposed the following decay scheme of ${ }^{40} \mathrm{~K}$ :

${ }^{40} \mathrm{~K}=>{ }^{40} \mathrm{Ca}+\beta^{-}$

In August 1937 C.F. von Weizsäcker developed the fundamental new idea of the dual beta decay of potassium. He argued that ${ }^{40} \mathrm{~K}$ decays not only to ${ }^{40} \mathrm{Ca}$, but also in a less significant degree to ${ }^{40} \mathrm{Ar}$. According to nuclear physics, ${ }^{40} \mathrm{~K}$ has the two stable isobars ${ }^{40} \mathrm{Ca}$ and ${ }^{40} \mathrm{Ar}$ of which the latter is the most abundant isotope in atmospheric argon. Von Weizsäcker recommended the investigation of a geologically old potassium mineral for the verification of his hypothesis.

A. Bramley published a paper in November 1937 on the $\gamma$ emission of ${ }^{40} \mathrm{~K}$. He presumed that the observed $\gamma$ rays require the capture of electrons by the nuclei of ${ }^{40} \mathrm{~K}$ rather than emission of $\beta^{+}$particles as suggested von Weizsäcker (1937). Electron capture (EC) occurs when the nucleus of an atom draws in an electron from an orbital of the lowest energy level. The net effect is that a nuclear proton is transformed into a neutron. The orbital vacancy is quickly filled by an electron that moves down from a higher energy level, and that energy difference appears as an X-ray photon. To explain the transmutation from ${ }^{40} \mathrm{~K}$ to ${ }^{40} \mathrm{Ar}$, Thomson and Rowlands (1943) studied experimentally the process of electron capture accompanied by gamma radiation. They observed characteristic $\mathrm{X}$-rays emitted when the electron vacancy in the lowest energy shell (K-shell) formed by the EC process is spontaneously filled by an electron from the upper L-shell.

Further investigations of potassium radioactivity were stopped by World War II, and thereafter a number of reports appeared in 1946 and 1947. A scheme of dual decay of ${ }^{40} \mathrm{~K}$ surprisingly close to the contemporary knowledge was published by von Hirzel and Wäffler (1946) from ETH Zürich (Fig. 5). Their scheme was based on the absorption measurements of $\beta$-rays in aluminum foils. They compared obtained absorption curve of $\beta$-rays to that determined earlier by K. Siegbahn for $\beta$-rays emitted by ${ }^{24} \mathrm{Na}$ isotope. They concluded that both absorption curves are identical, hence the maximum energy of $\beta$-rays emitted by ${ }^{40} \mathrm{~K}$ must be $1.41 \pm 0.02 \mathrm{MeV}$ ( $1 \mathrm{MeV}=10^{6}$ electron-volts), identical as that determined by Siegbahn. Gleditsch and Gráf (1947) from Oslo supplemented the decay scheme by relative proportions of the intensities of beta and gamma emissions.

Mayer et al. (1947) determined the energy of the $\gamma$ rays by their absorption in copper and lead. Their result of $1.5 \mathrm{MeV}$ agrees with that obtained earlier by von Hirzel and Wäffler (1946). They also performed coincidence measurements and found that $\beta^{-}$and $\gamma$ emission occurred independently from each other: $\gamma$-emission is solely accompanied by the electron capture, while $\beta^{-}$emission is related to the transition of ${ }^{40} \mathrm{~K}$ to ${ }^{40} \mathrm{Ca}$.

The maximum energy of the $\beta$ particles was precisely determined by Dželepow et al. (1946). They used a Danysz-type spectrometer to obtain the continuous kinetic energy spectrum of beta particles emitted by potassium (Fig. 6). Their result of $1.35 \pm 0.05 \mathrm{MeV}$ is accepted until present, though a number of its determinations have been made later on. The maximum energy of the $\beta^{-}$rays physically means the energy difference between the ground levels of the ${ }^{40} \mathrm{~K}$ and ${ }^{40} \mathrm{Ca}$ isobaric atoms. By means of the famous Einstein's formula, $E=m c^{2}$, the energy difference is equivalent to the mass difference of these isobars. In 1950 Roberts and Nier have measured a very small ${ }^{40} \mathrm{Ca}-{ }^{40} \mathrm{Ar}$ atom mass difference by a high resolving power mass spectrometer (dual-focusing) and they obtained (3.2 \pm 0.8$) \cdot 10^{-4}$ AMU (atomic mass units). Their result confirmed somewhat less precise results of $(2.7 \pm 2.1) \cdot 10^{-4}$ AMU obtained by Sailor (1949) from disintegration data. These determinations, with a known ${ }^{40} \mathrm{~K}-{ }^{40} \mathrm{Ca}$ mass difference (calculated from maximum energy of the $\beta^{-}$particles) and the energy of $\gamma$-rays, allowed calculating the energy of the excited state of ${ }^{40} \mathrm{Ar}$ nuclei. In this way they found that the excited level lies

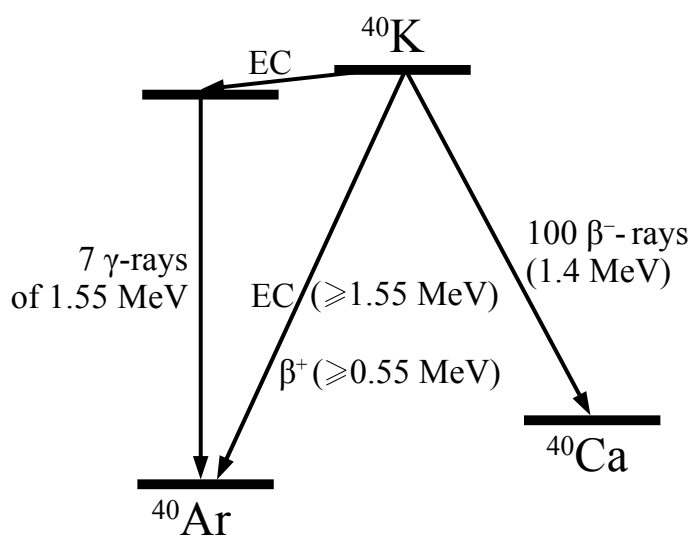

Fig. 5. Disintegration scheme for the decay of ${ }^{40} \mathrm{~K}$ (von Hirzel and Wäffler, 1946) with relative branching intensities from Gleditsch and Gráf (1947). 


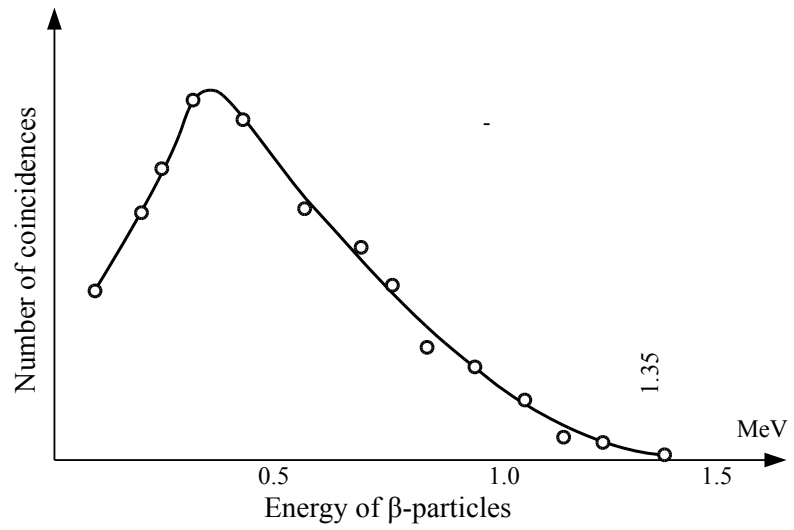

Fig. 6. Beta-ray spectrum of ${ }^{40} \mathrm{~K}$ obtained by Dželepow et al. (1946). The spectrum is continuous because the $\beta$ - particle (electron) shares the energy in every emission with another particle called neutrino. According to the theory of beta-decay (Fermi 1934) for both particles, which belong to fermions, the most probable energy partitioning is about $50 \%$ of the total energy. The maximum of the energy distribution is shifted towards lower energies due to attraction of $\beta$ - particles by positive charge of the nuclei.

only $(0.17 \pm 0.13) \mathrm{MeV}$ below the ground level of ${ }^{40} \mathrm{~K}$. This result definitely excludes any possibility of $\beta^{+}$ emission to this level, because $1.02 \mathrm{MeV}$ difference is necessary to emit a nearly resting positron $\left(\beta^{+}\right.$particle). This condition results from the principle of energy-mass conservation. Therefore the only possible transition from ground state of ${ }^{40} \mathrm{~K}$ to the excited state of ${ }^{40} \mathrm{Ar}$ is the electron capture, whereas both $\mathrm{EC}$ and $\beta^{+}$transitions to the ground state of ${ }^{40} \mathrm{Ar}$ are possible.

Finally at the end of the 60's it was well recognized that $\mathrm{EC}$ and $\beta^{+}$contributions to the ground state are really small and equal to $0.16 \%$ and $0.001 \%$, respectively (Beckinsale and Gale, 1969 and references therein). This was not as clear, however, at the end of 40's due to the appearance of confusing data of Bleuler and Gabrier (1947) regarding the EC rate. According to that paper the EC rate exceeds 1.9 times the rate of beta decay. "God only knows what they measured and how they obtained their results" comments Houtermans (1966). Their wrong data essentially delayed the development of K-Ar dating method.

\section{ARGON-40 IN POTASSIUM MINERALS}

In October 1948 Aldrich and Nier published their seminal paper on the first dating results with radiogenic argon determined with a very sensitive and selfconstructed mass spectrometer. About $0.1 \mathrm{~cm}^{3}$ gas (at standard temperature and pressure) degassed into an evacuated vessel from $400 \mathrm{~g}$ of minerals molten at $1000^{\circ} \mathrm{C}$

The mass spectrum of argon extracted from langbeinite, a potassium-magnesium sulfate mineral with formula: $\mathrm{K}_{2} \mathrm{Mg}_{2}\left(\mathrm{SO}_{4}\right)_{3}$ (Aldrich and Nier, 1948), provided evi- dence of ${ }^{40} \mathrm{Ar}$ excess in comparison with its content in atmospheric argon (Fig. 7). Assuming that all ${ }^{36} \mathrm{Ar}$ is atmospheric, they estimated the content of radiogenic argon in the samples and the branching ratio $\lambda_{\mathrm{EC}} / \lambda_{\beta}$ to be at least 0.02 , which was estimated on the basis of already known decay constant $\lambda_{\beta}$.

\section{FURTHER DEVELOPMENT OF POTASSIUM- ARGON DATING METHOD}

During the 1950 's and 1960 's, ${ }^{40} \mathrm{~K}-{ }^{40} \mathrm{Ar}$ dating was implemented in a number of laboratories around the world. Based on the studies by Aldrich and Nier (1948) and those listed in section 7, the decay of potassium-40 to ${ }^{40} \mathrm{Ar}$ emerged as a unique process suitable to dating of old rocks. The 10 times more frequent decay to ${ }^{40} \mathrm{Ca}$ is not suitable, because this isotope is too abundant in nature in order to precisely determine the traces of radiogenic ${ }^{40} \mathrm{Ca}$ in rock samples. Moreover, minute quantities of argon (and other noble gases) can be precisely measured with so called static-vacuum mass spectrometry instead of the dynamic flow mass spectrometry as used by Aldrich and Nier (1948). This ultra-sensitive technique was developed and described in detail by J. H. Reynolds at the University of California, Berkeley, in 1956. Very small noble gas samples were closed off within the spectrometer envelope (made of metalized pyrex glass) and analyzed under their low pressure inside the Reynolds' instrument. Recent all-

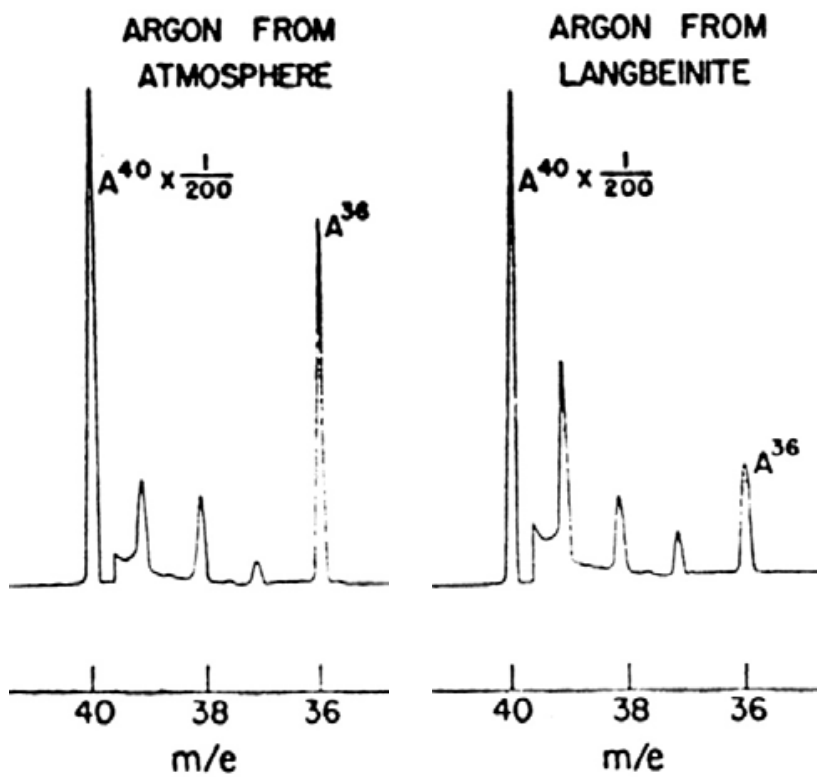

Fig. 7. The mass spectrum of atmospheric argon compared with that of radiogenic argon extracted from a sample of the potassium mineral langbeinite (Aldrich and Nier, 1948). Referring to the peak of ${ }^{36} \mathrm{Ar}$ there is an ${ }^{40} \mathrm{Ar}$ excess in langbeinite. The peaks 37 and 39 belong to the instrumental background, these peaks were seen also prior to argon admission, but the authors did not see any contaminants at masses of 36 and 40. 
metal version of this type instruments are commercially available and they are commonly used in isotope analysis of noble gases.

The K-Ar age is calculated from the decay formula (Eq. 4.1) under the following two basic assumptions: (i) there is no initial concentration of the radiogenic argon in the studied mineral, (ii) the mineral is treated as a closed system with respect to both elements Ar and K. The final formula for the time which elapsed from the mineral crystallization to present (see e.g. Halas, 1995, for its derivation) is:

$t=\frac{1}{\lambda} \ln \left(1+\frac{\lambda}{\lambda_{E C}} \cdot \frac{{ }^{40} \mathrm{Ar}^{*}}{{ }^{40} \mathrm{~K}}\right)$

where $\lambda$ is the total decay constant of ${ }^{40} \mathrm{~K}, \lambda_{E C}$ is the decay constant for the electron capture (Table 1), ${ }^{40} \mathrm{Ar}^{*}$ is the mole concentration of the radiogenic argon in the sample, and ${ }^{40} \mathrm{~K}$ is the mole concentration of the radioactive potassium- 40 . The last is calculated from the total concentration of potassium, $\% K$, in the mineral sample and the abundance of this isotope given in Table 1. The measurable total concentration of ${ }^{40} \mathrm{Ar}$ has to be corrected for atmospheric argon with the known ${ }^{40} \mathrm{Ar} /{ }^{36} \mathrm{Ar}_{\text {atm }}$ isotope ratio.

The classical K-Ar dating suffers from the fact that the potassium concentration is highly variable and inhomogeneous in rock minerals; it might in fact be different in the two parts of the same sample split up for the quantitative ${ }^{40} \mathrm{~K}$ and ${ }^{40} \mathrm{Ar}$ determinations. This drawback is partly overcome by the preparation of fine-grained $(\sim 100$ mesh) and well-mixed samples.

The method of the simultaneous determination of the concentrations of both isotopes was developed by Merrihue in the John H. Reynolds' laboratory, University of California, Berkeley in 1965. It is known as ${ }^{40} \mathrm{Ar}_{-}{ }^{39} \mathrm{Ar}$ method (Merrihue and Turner, 1966). The sample to be dated is irradiated together with a sample of known age in a nuclear reactor where the uptake of neutrons by ${ }^{39} \mathrm{~K}$ and simultaneous emission of protons produce ${ }^{39} \mathrm{Ar}$. The number of ${ }^{39} \mathrm{Ar}$ atoms is directly proportional to $\% \mathrm{~K}$. The irradiation of a sample with known age allows the determination of the "irradiation parameter" needed for the adaption of the age equation to the individual radiation

Table 1. Commonly used data in K-Ar dating (Steiger and Jäger, 1977).

\begin{tabular}{ll}
\multicolumn{2}{c}{ Decay constants: } \\
$\lambda_{\beta}$ & $4.962 \cdot 10^{-10} \mathrm{a}^{-1}$ \\
$\lambda_{\mathrm{EC}}$ & $0.581 \cdot 10^{-10} \mathrm{a}^{-1}$ \\
$\lambda_{\text {total }}$ & $5.543 \cdot 10^{-10} \mathrm{a}^{-1}$
\end{tabular}

sotopic abundances (\%):

$\begin{array}{lccr}{ }^{39} \mathrm{~K} & 93.2587 & { }^{36} \mathrm{Ar}_{\mathrm{atm}} & 0.337 \\ { }^{40 \mathrm{~K}} & 0.01167 & { }^{38} \mathrm{Ar}_{\mathrm{atm}} & 0.063 \\ { }^{41} \mathrm{~K} & 6.7302 & { }^{40} \mathrm{Ar} \text { atm } & 99.600\end{array}$

conditions in the reactor. Both argon isotopes are measured with the mass spectrometer. The ${ }^{39} \mathrm{Ar}$ peak is proportional to the content of radiogenic ${ }^{39} \mathrm{~K}$. This peak is corrected for the contribution of ${ }^{39} \mathrm{Ar}$ generated by neutrons from ${ }^{39} \mathrm{Ca}$. The ${ }^{40} \mathrm{Ar}$ peak has to be corrected for fraction of the atmospheric argon and that generated from potassium (McDougall and Harrison, 1988; Halas and Hess, 1990).

\section{ANALYTICAL PRECISION OF K-Ar DATES}

A necessary condition for reliable K-Ar dating is the most accurate determination of the content of potassium and argon in the samples. The application of the isotope dilution method is essential in achieving this goal by using a spike of highly enriched ${ }^{38} \mathrm{Ar}$. The required precision of radiogenic argon determination of at least $\pm 1 \%$ is nowadays best approached by the implementation of the isotope dilution method (Aldrich et al., 1953; Wasserburg and Heyden, 1955) after it was shown that the volumetric determinations are less successful. Dilution method is especially applicable in the cases when contents of mother and daughter isotopes differ widely. Important improvements of ultra-high vacuum line for gas extraction have been made by Staudacher et al. (1978). Their invention of a double vacuum furnace enabled extraction of noble gas for isotope analysis from extremely small quantities of minerals with low contamination by atmospheric argon.

Although a number of methods of the potassium concentration determination are offered by analytical chemistry, the most accurate appears to be the isotope dilution method (Webster, 1959; Zinkiewicz, 1980), in which a precisely weighted quantity of a ${ }^{41} \mathrm{KCl}$ spike is mixed with a weighted quantity of the sample. The isotope ratio ${ }^{39} \mathrm{~K} /{ }^{41} \mathrm{~K}$ of the mixture is measured with a thermal ionization mass spectrometer and the $\% K$ calculated with the following formula (Halas, 2001):

$\% K=A \cdot(M-S) /(N-M) \cdot m_{\mathrm{s}} / m_{\mathrm{N}}$,

where $m_{\mathrm{s}}$ and $m_{\mathrm{N}}$ are masses of the spike and the sample, respectively, $A$ is a calibration constant (dependent on the ${ }^{41} \mathrm{~K}$ concentration in the spike), and $N, S, M$ denote the isotope ratios ${ }^{39} \mathrm{~K} /{ }^{41} \mathrm{~K}$ in the natural sample to be dated, the spike and the mixture, respectively. The $N$ and $S$ values are known, whilst only $M$ is determined by means of mass spectrometry. The $m_{\mathrm{s}} / m_{\mathrm{N}}$ ratio is chosen (on the basis of roughly known or expected $\% K$ in the sample) to determine $M$ far from both $N$ and $S$ in order to achieve the best precision. With this method the age of samples with potassium concentration as low as $0.01 \%$ (e.g. in meteorites) can be accurately determined with analytical precision of $\pm 0.1 \%$.

The same procedure is applied to the argon isotopes applying a highly enriched ${ }^{38} \mathrm{Ar}$ spike. The precision of the radiogenic argon determination strongly depends on 
its fraction in measured quantity of total ${ }^{40} \mathrm{Ar}$. The fraction of ${ }^{40} \mathrm{Ar} *$ is usually high in old samples, usually much above $50 \%$, and its relative standard deviation may not exceed $\pm 1 \%$. However, in the case of Quaternary samples with ${ }^{40} \mathrm{Ar} *$ as low as a few percent or less, the precision may not be better than $\pm 4 \%$ (Cox and Dalrymple, 1967).

The total relative standard deviation of a $\mathrm{K}-\mathrm{Ar}$ date $\left(\sigma_{t} / t\right)$ results from both relative standard deviation according to the error propagation formula:

$$
\frac{\sigma_{t}}{t}=G \cdot\left[\left(\frac{\sigma\left({ }^{40} K\right)}{{ }^{40} K}\right)^{2}+\left(\frac{\sigma\left({ }^{40} A r^{*}\right)}{{ }^{40} A r^{*}}\right)^{2}\right]^{\frac{1}{2}},
$$

where $\mathrm{G}$ is the following time-dependent factor: $\left(1-e^{-\lambda t}\right) / \lambda t$, which is close to unity for young samples (for $t$ below $100 \mathrm{Ma}$ ) and drops gradually down to 0.4 for $t=4 \mathrm{Ga}$.

\section{RELIABILITY OF K-Ar DATING METHOD}

Nowadays the K-Ar and Ar-Ar dating methods belong to the most reliable and the most significant methods in geochronology. Many boundaries of the global chronostratigraphic table of the Earth are based on K-Ar dates. However, there are samples which suffered from the loss of radiogenic argon during metamorphic and geothermal processes. Then the assumption of the closed systems with respect to $\mathrm{Ar}$ and also $\mathrm{K}$ for reliable $\mathrm{K}-\mathrm{Ar}$ dating is no longer fulfilled. Such open system cases lead to erroneous results which can be corrected using adequate models. The rough uncorrected dates are larger or smaller depending on the used methods. The resulting "geological errors" may be recognized and often also eliminated by the application of ${ }^{40} \mathrm{Ar}^{*-}{ }^{39} \mathrm{Ar}$ method to different kinds of minerals (McDougall and Harrison, 1988; Halas and Hess, 1990). The isochron method (Faure and Mensing, 2005) may also be helpful, and it can be applied to different coeval minerals if argon excess is present in the studied samples, i.e. when the initial quantity of ${ }^{40} \mathrm{Ar}$ is not negligible.

\section{ACKNOWLEDGEMENTS}

I was inspired by prof. A.K. Wróblewski's lecture presented during the $34^{\text {rd }}$ Meeting of Polish Physicists held in Katowice in September 1977. That lecture was published in the Meeting's issue (Wróblewski, 1997). I had full access to the historical literature at The University of Calgary during my visit in 1997.

I dedicate this paper to my former students, Dr. Tomasz Durakiewicz from Los Alamos National Laboratory, Dr. Artur Wójtowicz from UMCS, and Prof. Adam Kamiński from Iowa State University, for their contributions in the development of the instrumentation for $\mathrm{K}-\mathrm{Ar}$ dating at Maria Curie-Sklodowska University.
I am cordially grateful to unknown reviewer for his comments, numerous corrections, advices and encouragement for a significant improvement of the manuscript.

\section{REFERENCES}

Aldrich LT and Nier AO, 1948. Argon 40 in potassium minerals. Physical Reviews 74(8): 876-877, DOI 10.1103/PhysRev.74.876.

Aldrich LT, Doak JB and Davis GL, 1953. The use of ion exchange columns in mineral analysis for age determination. American Journal of Science 251(5): 377-387, DOI 10.2475/ajs.251.5.377.

Aston FW, 1921. The mass spectra of the alkali metals. Philosophical Magazine Ser. 6 42(249): 436-441, $\quad$ DOI $10.1080 / 14786442108633780$.

Aston FW, 1933, 1941. Mass Spectra and Isotopes, $1^{\text {st }}$ and $2^{\text {nd }}$ Editions, Longmans, London.

Baxter GP and MacNevin WM, 1933. A revision of the atomic weight of potassium, Journal of American Chemical Society 55(8): 3185-3190, DOI 10.1021/ja01335a020.

Beckinsale RD and Gale NH, 1969. A reappraisal of the decay constants and branching ratio of ${ }^{40} \mathrm{~K}$. Earth and Planetary Science Letters 6: $289-294$.

Bleuler E and Gabrier M, 1947. Zerfall des $\mathrm{K}^{40}$. Helvetica Physica Acta 20: 67 .

Boltwood BB, 1907. On ultimate disintegration products of the radioactive elements. American Journal of Science 20(118): 253-267, DOI 10.2475/ajs.s4-20.118.253.

Biltz M and Ziegert UH, 1928. Die Radioaktivität der Isotope des Kaliums (Radioactivity of the isotopes of potassium). Physikalische Zeitschrift 29: 197-200 (in German).

Bramley A, 1937. The potassium-argon transformation. Science: 86 : 424-425, DOI 10.1126/science.86.2236.424.

Brewer AK, 1935. Further evidence for the existence of $\mathrm{K}^{40}$. Physical Reviews 48(7): 640-640, DOI 10.1103/PhysRev.48.640.

Cox A and Dalrymple GB, 1967. Statistical analysis of geomagnetic reversal data and the precision of potassium-argon dating. Journal of Geophysical Research 72(10): 2603-2614, DOI 10.1029/JZ072i010p02603.

Curie P and Curie Mme P, 1898. Sur une substance nouvelle radioactive, contenue dans la pechblende. Comptes rendus 127: 175-178.

Curie P, Curie Mme P and Bémont G, 1898. Sur une nouvelle substance fortement radioactive, contenue dans la pechblende. Comptes rendus 127: 1215-1217.

Curie P, 1905. Nobel lecture "On radioactive substances". In: Nobel Lectures in Physics 1901-1921. Elsevier, Amsterdam 1967.

Dželepow E, Kopjova M and Vorobjov E, 1946. Beta-ray spectrum of K-40. Physical Review 69(9-10): 538-539, DOI 10.1103/PhysRev.69.538.2.

Fajans K, 1913. Radioactive transformations and the periodic system of the elements. In: Berichte der Deutschen Chemischen Gesellschaft 46: 422-439.

Faure G and Mensing TM, 2005. Isotopes - Principles and Applications ( $3^{\text {rd }}$ edition). New Jersey, Wiley: $928 \mathrm{pp}$.

Fermi E, 1934. An attempt of a theory of beta radiation. 1. (in German) Zeitschrift für Physik 88: 161-171; A complete English translation is given by: Wilson FL, 1968. Fermi's theory of beta decay, American Journal of Physics 36: 1150-1160.

Fermi E, Amaldi E, Pontecorvo B, Rasetti F and Segre E, 1934. La Ricerca Scientifica 2, No. 7-8, No. 9-10.

Gleditsch E and Gráf T, 1947. On the gamma-rays of $\mathrm{K}^{40}$. Physical Reviews 72(7): 640-641, DOI 10.1103/PhysRev.72.640.

Halas S, 1998. From Discovery of polonium and radium to explanation of branched decay of potassium-40. Postepy Fizyki 49: 268-273 (in Polish).

Halas S, 1995. Isotope geochronology based on radioactive decay of potassium. Przeglad Geologiczny 43: 993-998 (in Polish).

Halas S, 2001. Chemical analysis of elements by isotope dilution on the example of potassium determination in minerals dated by $\mathrm{K}-\mathrm{Ar}$ metod. Elektronika 42: 53-55 (in Polish). 
Halas S and Hess J, 1990. Physical foundations of Datong by the K-Ar and ${ }^{40} \mathrm{Ar}{ }^{39} \mathrm{Ar}$ methods. In: Jędrysek MO, ed., Course-book of Isotope Geology. Wrocław University and Committee on Mineralogical Sciences: 184-200.

von Hevesy G, 1935. Die Radioaktivität des Kaliums. Naturwissenschaften: 23(34): 583-585, DOI 10.1007/BF01492377.

von Hirzel O and Wäffler H, 1946. Über die beim Zerfall des $\mathrm{K}^{40}$ emittierte $\gamma$-Strahlung. Helvetica Physica Acta 19: 216-217.

Houtermans FG, 1966. History of the K-Ar method of geochronology, In:Schaeffer OA and Zähringer J (Editors), Potassium Argon Dating, Springer-Verlag, Berlin : 234 pp.

Merrihue C and Turner G, 1966. Potassum-argon dating by activation with fast neutrons. Journal of Geophysical Research 71: 28522857, DOI . 10.1029/JZ071i011p02852

McDougall I and Harrison TM, 1988. Geochronology and Thermochronology by the ${ }^{40} \mathrm{Ar}{ }^{39} \mathrm{Ar}$ Method. Oxford University Press, New York: $212 \mathrm{pp}$.

Meyer HA, Schwachheim G and de Souza Santos MD, 1947. Decay of $\mathrm{K}^{40}$. Physical Review: 71(12): 908-908, DOI 10.1103/PhysRev.71.908.

Newman FH and Walke HJ, 1935. The radioactivity of potassium and rubidium. Philosophical Magazine Series 7 19(128): 767-773, DOI $10.1080 / 14786443508561414$.

Nier AO, 1935. Evidence for the existence of an isotope of potassium of mass 40. Physical Reviews 48(3): 283-284, DOI 10.1103/PhysRev.48.283.

Reynolds JH, 1956. High sensitivity mass spectrometer for noble gas analysis. The Review of Scientific Instruments 27(11): 928-934, DOI 10.1063/1.1715415.

Roberts TR and Nier AO, 1950. The ${ }^{40} \mathrm{~K}-{ }^{40} \mathrm{Ar}$ mass difference and the radioactivity of ${ }^{40} \mathrm{~K}$. Physical Review 79: 198.

Rutherford E, 1906. Radioactive Transformations. Scribner's Sons, New York: 287pp.

Rutherford E and Soddy F, 1902a. The Cause and Nature of Radioactivity - Part II. Philosophical Magazine 6 4(21): 370-396, DOI 10.1080/14786440209462856.

Rutherford E and Soddy F, 1902b. The Cause and Nature of Radioactivity I, II. Philosophical Magazine 6 4(23): 569-585, DOI $10.1080 / 14786440209462881$.
Sklodowska-Curie M, 1898. Rayons émis par les composés de l'uranium et du thorium (english translation Emission of rays by uranium and thorium compounds). Comptes Rendus 126 (JanJune): 1101-1103.

Sailor VL, 1949. Energy levels in ${ }^{41} \mathrm{Ca}$ and the mass difference between ${ }^{40} \mathrm{Ar}$ and ${ }^{40} \mathrm{Ca}$. Physical Review 75(12): 1836-1839, DOI 10.1103/PhysRev.75.1836.

Smythe WR and Hemmendinger A, 1937. The radioactive isotope of potassium. Physical Reviews 51: 178-182, DOI 10.1103/PhysRev.51.178.

Soddy F, 1911. The Chemistry of Mesothorium, Journal of Chemical Society 99: 72-83, DOI 10.1039/CT9119900072.

Soddy F, 1913. The Radio Elements and the Periodic Law. Chemical News 107: 97-99.

Staudacher Th, Jessberger EK, Dorflinger D and Kiko J, 1978. A refined ultra-high vacuum furnace for rare gas analysis. Journal of Physics E: Scientific Instruments 11(8): 781-784, DOI 10.1088/0022-3735/11/8/019.

Steiger RH and Jäger E, 1977. Subcommission on geochronology: Convention on the use of decay constants in geo- and cosmochronology. Earth and Planetary Science Letters 36(3): 359-362, DOI 10.1016/0012-821X(77)90060-7.

Thomson JJ, 1905. On emission of negative corpuscles by alkali metals. Philosophical Magazine Series 6 10(59): 584-390, DOI 10.1080/14786440509463405.

Thompson FC and Rowlands S, 1943. Dual decay of potassium. Nature 152(3847): 103-103, DOI 10.1038/152103a0.

von Weizsäcker CF, 1937. Über die Möglichkeit eines dualen $\beta$ - Zerfalls von Kalium. Physikalische Zeitschrift 38: 623-624.

Wasserburg GJ and Heyden RJ, 1955. ${ }^{40} \mathrm{Ar}^{40} \mathrm{~K}$ dating. Geochimica et Cosmochimica Acta 7: 51-60.

Webster RK, 1959. Analysis by the method of isotope dilution. In: Waldron JD, ed., Advances in Mass Spectrometry. Pergamon Press, London 1959 (Russian translation, Moskwa 1963): 732 pp.

Wróblewski AK, 1997. Materiały XXXIV Zjazdu Fizyków Polskich (Proceedings of 34-th Meeting of the Polish Physical Society). Deni-Press, Katowice: 77 pp (in Polish).

Zinkiewicz JM, 1980. Method of isotope dilution. In: Żuk W, ed., Spektrometria mas $i$ elektromagnetyczna separacja izotopów. Polish Scientific Publishers (PWN), Warszawa: 490 pp (in Polish). 